\title{
The Simplified of Suspended Sediment Measurement Method in Natural River (Case study of Kuning River in Yogyakarta, Indonesia)
}

\author{
Bambang Agus Kironoto, Bambang Yulistiyanto*, Bangun Giarto, Mariatul Kiptiah, \\ Muhammad Lutfi Tantowi \\ Civil and Environmental Engineering Department, Faculty of Engineering, Universitas Gadjah Mada, INDONESIA \\ *Corresponding authors: bambangyulistiyanto@gmail.com
}

SUBMITTED 27 June 2019 REVISED 28 August 2019 ACCEPTED 12 September 2019

\begin{abstract}
The accumulation of suspended sediment reduces the capacity in the river and deteriorates the water quality. Kuning River in Yogyakarta is one of the main rivers in Yogyakarta, Indonesia, which is currently facing the issue of suspended sediments. To reduce the effect of suspended sediment and determine a preventive measure, hence, it is necessary to study the characteristics of the suspended sediment flow. Therefore, this study aims to investigate the suspended sediment flow characteristics, i.e. the velocity, and the concentration profiles at specific points in the transverse direction of the channel as well as the correlation of the suspended sediment discharge. Thirty (30) profiles of velocity and suspended sediment concentration were measured at six different points along the Kuning River. Opcon probe was used to measure suspended sediment concentration, while the propeller current meter was used to measure mean pointvelocity profiles. Results of this study show the suspended sediment discharge ratio, defined as $\left(\bar{U}_{y} \bar{C}_{y}\right) /(\bar{U} \bar{C})$ are higher in the middle part of the channel than the one near the edge of the channel. The position of $z / B$ where the values of $\left(\bar{U}_{y} \bar{C}_{y}\right) /(\bar{U} \bar{C})=1$ occurs at $z / B=0,19$ and $z / B=0,75$, which depend on the irregularity of the channel cross-sections. For practical purposes, the depth-averaged velocity and suspended sediment concentration can be determined from 1,2 and/or 3 points measurement at $\mathrm{y}=0,2 D, 0,4 D$ and $0,8 D$.
\end{abstract}

KEYWORDS Natural river; Field measurement; Measuring position; Velocity; Suspended sediment

(c) The Author(s) 2019. This article is distributed under a Creative Commons Attribution-ShareAlike 4.0 International license.

\section{INTRODUCTION}

Studies of suspended sediment are essential and very important in the environmental study since the existence of suspended sediment can reduce the capacity and the quality of water channels hence it affects the function and reduces the design life of hydraulic structure such as a reservoir, a sand trap, an irrigation canal, etc. The issues of suspended sediments in the river are relatively complex due to the lack of data availability and the unsatisfactory results given by various mathematical models. The challenge of those mathematical models might arise due to uncertainty or irregularity of parameters, such as river walls, the cross-sectional shape of the river, and the roughness of the river bed. Several studies are looking for new models and evaluating the existing methods and empirical models to accurately estimate the suspended sediment load (Muste \& Patel, 1997; Shah-Fairbank ShahFairbank, et al., 2011; Lv, S, et al., 2015). In addition to the empirical formula, the sediment rating curve has been used to estimate the suspended sediment; however, significant uncertainty is still observed (Heng and Suetsugi, 2014). Various soft computing techniques have also been developed to predict suspended sediment which one of the methods is Stacking method. This method introduces a linear genetic programming and neuro-fuzzy methods to estimate suspended sediment (Shamei \& Kaedi, 2016).

A study by Bartram, J \& Balance, R (1996) reports the complete measurement across the flow section of the natural river is required to determine the suspended sediment discharge. 
The distribution of suspended sediment particles, as well as the concentration of suspended sediment, vary significantly in vertical depth and all parts of the flow channel; therefore, measuring of suspended sediment concentration should consider these such variations. Gray. J.R \& Landers, M.N (2014) shows the activities of sampling of suspended sediment, and measuring of velocity in a channel for determining suspended sediment discharge should be conducted throughout the whole channel crosssection.

A square-shaped channels study conducted by Kironoto (2007) shows the location of the suspended discharge ratio is equal to one $(1,0)$ takes place at the position of $z / B=0.2$ and 0.8 , where $B$ is the width of the channel. Further, a study of Kironoto and Yulistiyanto (2016) conducted a study in trapezoidal channels, obtained the value of at $z / B=0.25$ and 0.75 . Kironoto and Yulistiyanto (2009) describe the Rouse equation could estimate the suspended sediment concentration profiles accurately if the data are measured at the centre of the channel and it can be applied either for laboratory or field scale. However, for a case where data is collected far from the centre of the channel (close to the channel side banks), result from Rouse equation deviates from the measured data

Although many methods have been proposed, however, many researchers admit the most reliable way to determine the suspendedsediment discharge in the channel is through direct measurement of the flow rate combined with the measurement of the suspended sediment concentration for certain period. According to the issues above, hence, the study of suspended sediment flow characteristics was conducted by investigates the profiles of velocity and suspended sediment concentration. Furthermore, this study attempts to develop a method to determine the correlation between suspended sediment discharge and sampling location, etc.

Kuning river was selected to be a case study since it plays an important role in nature, especially as a drainage system in the Special Region of
Yogyakarta, Indonesia. Kuning River locates at coordinate $7^{\circ} 46^{\prime} 33.06^{\prime \prime} \mathrm{S}$ and $110^{\circ} 28^{\prime} 30.13^{\prime \prime} \mathrm{E}$. Kuning River is a natural river with a length of about $40 \mathrm{~km}$, where the upstream part source at the summit of Mount Merapi. Merapi Mount with a summit elevation of 2,930 m.a.s.l. and is located on the border between Central Java and Special Region of Yogyakarta, is one of the most active volcanoes in Indonesia. Since 1548, Merapi Mount has erupted 68 times, and the last eruption occurred in 2010. Like most of the natural rivers, Kuning River serves as a medium to drain the water; it also serves as a medium to transport the material as a sediment flow.

\section{MATERIALS AND METHODS}

Several variables were measured in this study. They are grouped as the point-velocity and the suspended-sediment measurements, and the other group measurements, such as flow depth, water temperature, and free water surface slope. The mean point-velocity profiles were measured by using a calibrated propeller current meter $\mathrm{C} 2$ type 10".150" No.95384. While the suspended sediment concentration profiles were measured by using Opcon probe coupled with the Opcon control-unit of a signal processor - with an output capacity of $0-10$ volts DC - and connected to a computer for data acquisition and further data processing. Signal processor has a frequency response of $1 \mathrm{~Hz}(-3 \mathrm{~dB})$ with accuracy level or zero stability $0.4 \% / 24$ hours. Opcon is an instrument specifically designed for measurement of suspended particle concentration in the field; together with the Opcon control-unit, allowing to detail nonsampling measurements with negligible process disturbances in the channel flow. Opcon probe works based on attenuation of light intensity due to light absorption and reflection of suspended silt particles. The Points Measurement Method was applied to obtain suspended sediment concentration and mean point velocity profiles. The measurements were conducted at six different locations (S1, S2, S3, S4, S5, and S6) along Kuning River. For each location, the measurements of velocity and suspended sediment concentration were conducted at five 
measuring verticals, i.e., at V1, V2, V3, V4, and V5.

\subsection{Flow Measurements}

Some hydraulic parameters were evaluated in this study; namely friction velocity, roughness coefficient, depth-averaged and cross-section mean velocities, depth-averaged and crosssection mean suspended sediment concentrations, as well as 1, 2, and 3-points of velocity and suspended sediment measurements. The friction velocity, $u^{*}$, and the $B r$-value, which represents the integration constant of logarithmic velocity distribution can be calculated by using the Clauser method. The equation of logarithmic velocity distribution (loglaw), is given as:

$\frac{u_{y}}{u_{*}}=\frac{1}{\kappa} \ln \left(\frac{y}{k_{s}}\right)+B r$

together with the measurement data of velocity profiles in the inner region $-y / D \leq 0.2$, where $D$ is the flow depth - were used to determine the friction velocity, $u *$. In Eq. (1), $y$ is the distance from the channel bed to a measurement point, $\kappa$ is a Von Karman's constant, and $k_{s}$ is the Nikuradse roughness values

The Nikuradse roughness value, ks, can be determined according to the following equation (Graf \& Altinakar, 1998):

$\frac{C}{\sqrt{g}}=\sqrt{\frac{8}{f}}=5.6\left(\frac{R}{k_{s}}\right)+6.25$

where $\mathrm{Cc}$ is the Chezy coefficient, $\mathrm{f}$ is the friction coefficient, and $\mathrm{R}$ is the hydraulic radius. The depth-averaged velocity, $\bar{U}_{y}$, can be determined as (Kironoto, B.A. \& Yulistiyanto, B, 2016).

$\bar{U}_{y}=\frac{1}{D} \int_{0}^{D} u_{y} d y$

For practical purposes, the depth-averaged velocity is often determined based on 1,2 and 3 points measurement, according to the following equations (Kiptiah, M, 2016):

$\bar{U}_{y}=U_{0.4 D}$

$$
\bar{U}_{y}=\left(\frac{1}{2} U_{0.4 D}+\frac{1}{2} U_{0.8 D}\right)
$$

$\bar{U}_{y}=\left(\frac{1}{4} U_{0.2 D}+\frac{1}{2} U_{0 . .4 D}+\frac{1}{4} U_{0.8 D}\right)$

where $\bar{U}_{y}$ is the depth-averaged velocity, $U_{0,2 D}$, $U_{0,4 D}$, and $U_{0,8 D}$, respectively, is mean pointvelocity at $0,2 \mathrm{D}, 0,4 \mathrm{D}$, and $0,8 \mathrm{D}$ from the channel bed, and D is the flow depth. The cross-section mean velocity, $\bar{U}^{-}$, can be obtained as follows

$\bar{U}=\frac{\bar{U}_{y 1} A_{y 1}+\cdots+\bar{U}_{y n} A_{y n}}{\left(A_{y 1}+A_{y 2}+\cdots+A_{y n}\right)}$

where $\bar{U}_{y 1}$ and $\bar{U}_{y n}$ are the depth-averaged velocity at element cross-section 1 and $n$, respectively, while $A_{y 1}$ and $A_{y 2}$, respectively is the element cross-section 1 and $n$. The flow discharge, $Q$, then can be calculated as:

$Q=\bar{U} A$

where A is the total channel cross-section.

\subsection{Sediment Concentration Distributions}

Suspended sediment concentration distribution, C, can be determined by using Rouse equation (1937, given in Graf, 1984; Garde \& Raju, 1997) as follows:

$\frac{C}{C_{a}}=\left(\frac{D-y}{y} \frac{a}{D-a}\right)^{Z}$

or by using Tanaka and Sugimoto equation (1958; as provided in (Garde, R.J \& Raju, K.G.R. , 1997)

$\frac{C}{C_{a}}=\left[\left(\frac{\sqrt{D}+\sqrt{D-y}}{\sqrt{D}-\sqrt{D-y}}\right)\left(\frac{\sqrt{D}-\sqrt{D-a}}{\sqrt{D}+\sqrt{D-a}}\right)\right]^{Z}$

where $\mathrm{D}$ is the flow depth, $\mathrm{C}$ and $\mathrm{Ca}$, is respectively, the suspended sediment concentration at a distance y and a distance a $(\approx$ $0,05 \mathrm{D}$ ) from the channel bed, ws, is the fall velocity of suspended sediment, and $\kappa$ is a Von Karman's constant. In Eqs. (9) and (10), Z, is defined as

$u Z=\frac{w_{s}}{u_{*} \kappa}$

which refer to Rouse parameter. The depthaveraged of suspended sediment concentration, $\bar{C}_{y}$, can be calculated using the following equation 
(Giarto, B.R, 2016; Kironoto, B.A \& Yulistiyanto, $\mathrm{B}$, 2016):

$\bar{C}_{y}=\frac{1}{D-a} \int_{a}^{D} C d y$

Similar to Eqs. (4), (5), and (6) which commonly used for determining the depth-averaged velocities, the depth-averaged of suspended sediment concentration can also be determined based on 1, 2 and 3 points measurement of suspended sediment concentration, according to the following equations (Garde, R.J \& Raju, K.G.R. , 1997; Tantowi \& M. Lutfi, 2016; Kironoto, B.A, 2008).

$\bar{C}_{y}=\operatorname{Cte}_{1} \cdot C_{0.4 D}$

$\bar{C}_{y}=$ Cte $_{2} \cdot\left(\frac{3}{8} C_{0.2 D}+\frac{5}{8} C_{0.8 D}\right)$

$\bar{C}_{y}=C t e_{3} \cdot\left(\frac{3}{16} C_{0.2 D}+\frac{8}{16} C_{0.4 D}+\frac{5}{16} C_{0.8 D}\right)$

where $\mathrm{Cte}_{1}, \mathrm{Cte}_{2}$, and $\mathrm{Cte}_{3}$ are constants values can be determined from data measurement,$- \bar{C}_{y}$, is the depth-averaged of suspended sediment concentration, $C_{0,2 D}, C_{0,4 D}$, and $C_{0,8 D}$ are suspended sediment concentrations at points $0,2 D, 0,4 D$, and $0,8 D$ from the channel bed, respectively; for a rectangle-shaped channel, both in laboratory and in-field irrigation channels, the values of constants are about to one, Cte $_{1} \approx$ Cte $_{2} \approx$ Cte $_{3} \approx 1$, as obtained by Kironoto (2008). The cross-section suspended sediment concentration, $\bar{C}$ can be obtained as:

$\bar{C}=\frac{\bar{C}_{y 1} A_{y 1}+\cdots+\bar{C}_{y n} A_{y n}}{\left(A_{y 1}+A_{y 2}+\cdots+A_{y n}\right)}$

where $\bar{C}_{y 1}$ and $\bar{C}_{y n}$, respectively is the depthaveraged of suspended sediment concentration at element 1 and element $n$; while $A_{y 1}$ and $A_{y 2}$ respectively is the element cross-section 1 and $n$. The suspended sediment discharge, Qs, then can be calculated by:

$Q_{s}=\bar{U} \bar{C}$

\section{RESULTS AND DISCUSSIONS}

\subsection{Main parameter}

Thirty (30) profiles of mean point velocity and suspended sediment concentration have been measured in the study. Each profile have a code name with five different alphabets; the first alphabet represents the first name of Kuning River (K), the second and the third alphabets represent the slopes of free water surface at each measuring sections (S1, S2, .., S6), and the fourth and the fifth alphabets represent the vertical measuring positions in transversal direction at each cross-section (V1, V2, ..., V5).

(a)

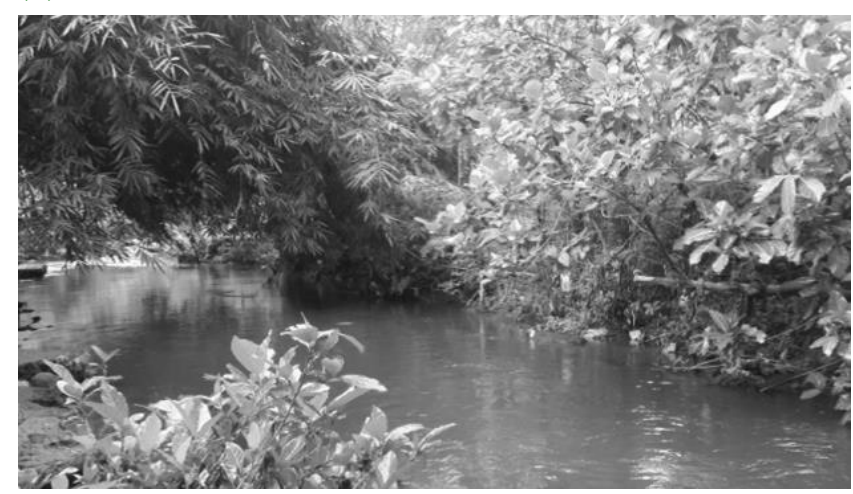

(b)

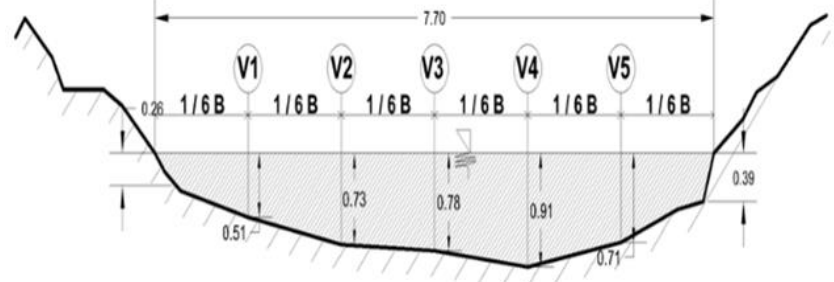

Figure 1. The photographs (a) and measuring verticals (b) in the transverse direction at location section, S3, of Kuning River.

\subsection{Velocity Data}

Figure 2 presents typical examples of velocity profile measured in section 5 . As can be seen from Figure 2, the highest velocities located at the middle part of the channel, i.e. at KS5V3 and KS5V4, and then decrease at the locations closer to the channel edges. The trend of velocity profiles at five other sections along the Kuning river is similar to the results of the study 
conducted by Kironoto, B.A \& Yulistiyanto, B. (2016b).

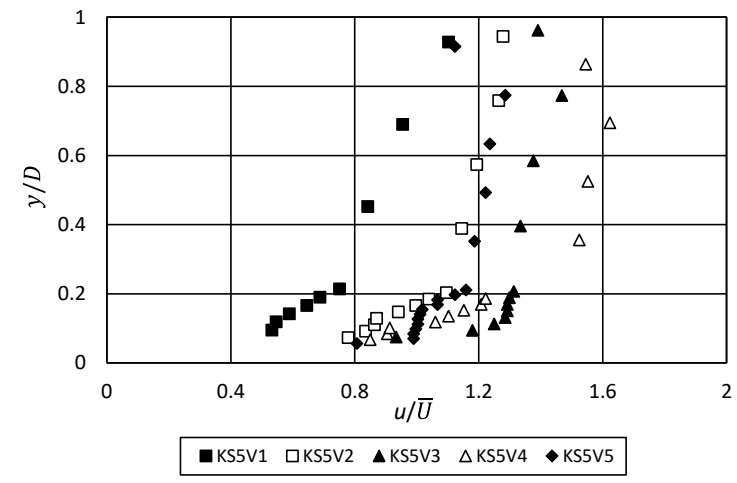

Figure 2. A typical example of velocity profiles in section 5

The depth-averaged velocity at each vertical section was determined by integrating the velocity profiles data from the bed or reference level to the free water surface and dividing it with flow depth. The depth-averaged velocities obtained in this study are presented in Figure 3, where the depth-averaged velocities at each measuring verticals are normalized by the crosssection averaged velocity of each section, $\bar{U}_{y} / \bar{U}$ vs. z/B. It is shown from Figure 3 that the depthaveraged velocity reaches its maximum value at the centre part of each cross-section, and decrease in approaching to the edges of the channel.

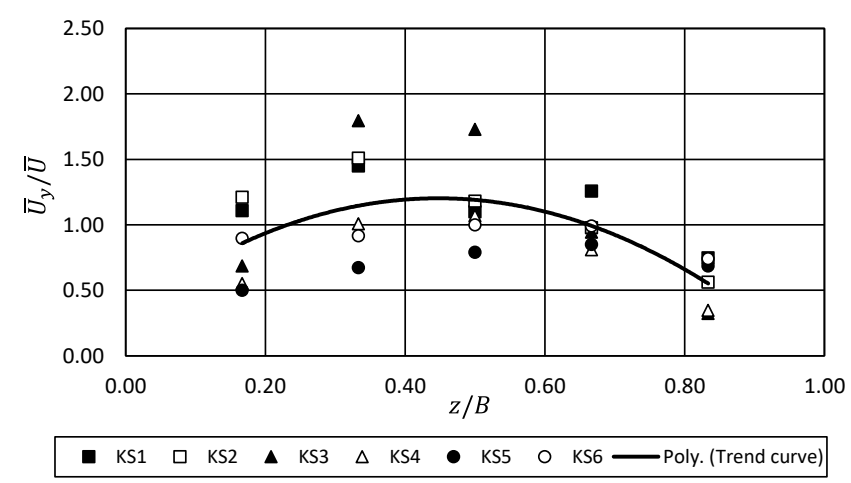

Figure 3. The normalised depth-averaged velocity to the cross-section averaged velocity, $\bar{U}_{y} / \bar{U}$ vs. $z / B$.

Figure 3 shows the scattered data are significantly observed from one section to another. Profile from section 1 (KS1) to section 6 (KS6) is affected by the irregularity of each cross-section, abrupt changes in cross-sectional geometry, and other types of obstruction, such as riverbed variation, channel bed slope, channel sidewall slope, bed and wall roughness, aquatic vegetations in Kuning River. However the influence of each factor can not be observed separately from the data.

Based on the data measured at six different sections along Kuning River, the depth-averaged velocity at $z / B \approx 0.25$ and $z / B \approx 0,65$ represent the cross-section averaged velocity, i.e., $\bar{U}_{y} / \bar{U}=1$. These positions vary for each section depends on the position of the main flow, as well as the slopes of the channel side banks.

For a regular and prismatic trapezoidal crosssection with the slopes of the channel side wall varies from $1: 1,0$ to $1: 1,6$, the value of $\bar{U}_{y} / \bar{U}=1$ occurs at $z / B \approx 0,25$ and $z / B \approx 0,75$, as reported by (Kironoto, B.A. \& Yulistiyanto, B. , 2016a).

Using the measured velocity profiles obtained in the inner region, the friction velocity, $u_{*}$, can be analysed by applying the Clauser Method. Velocities, $u$, derived from the measurement are plotted against their positions from the channel bed, $\ln \left(y / k_{s}\right)$, as given in Figure 4 . As presented in the figure, the measurement points in the inner region, $y / D<0.2$, follow a logarithmic velocity distribution and deflect from a logarithmic line in the outer area, in particular locations near the free water surface. The same trends were also reported by Cardoso, A. H, et al., (1989) and Guo, J \& Julien, P.Y. (2001). The Nikuradse roughness coefficients, $k_{s}$, used in the Clauser methods, can be determined from the slope of free water surface, $S_{w}$. Assuming that the flow is uniform, the friction slope is defined to be equal to the free water surface slope and determines the Chezy coefficient, $C_{C}=\bar{U} /\left(R S_{w}\right)^{1 / 2}$, the values of $k_{s}$ can be calculated by using Eq. (2).

Results of friction velocity calculated by Clauser method for all velocity profile data are given in Figure 5. The friction velocity at measuring verticals and normalised by their averaged friction velocity of each cross-section, $u_{*} / \bar{u}_{*}$, are plotted against the distance from the channel sidewall, $z / B$. 


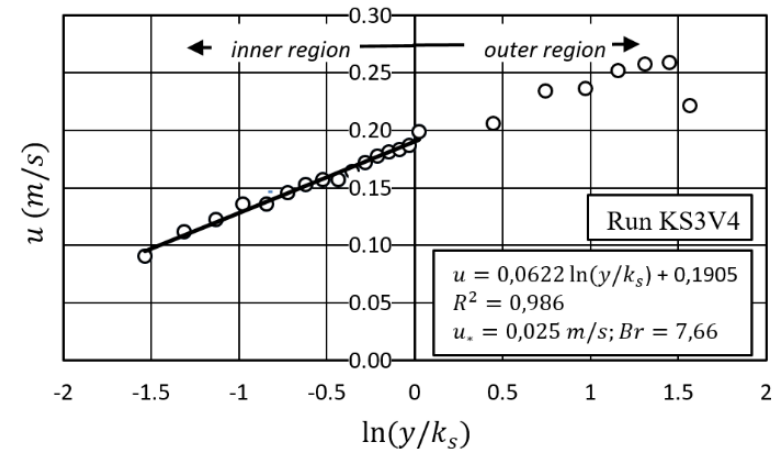

Figure 4. A typical example of friction velocity, $u_{*}$, calculated using Clauser's Method

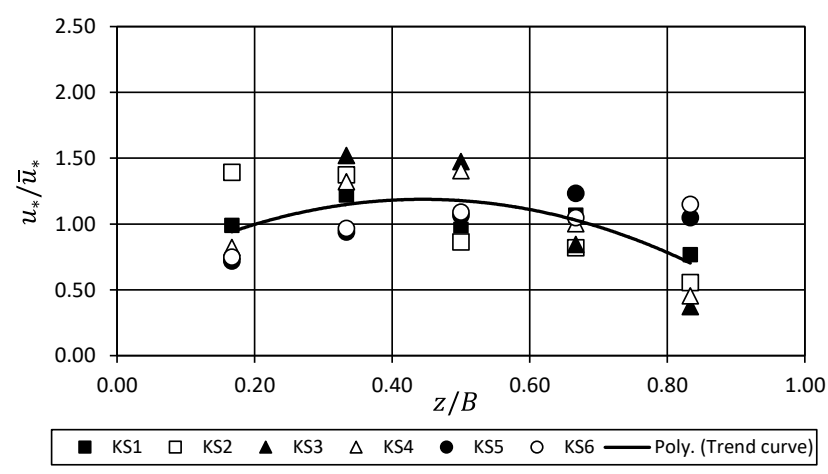

Figure 5 . The plot of friction velocity, $u_{*} / \bar{u}_{*}$, against $z / B$.

In the figure, the position of $u_{*} / \bar{u}_{*}=1$, located at $z / B \approx 0.20$ and $z / B \approx 0.65$, which might also depend on the position of the main flow and the slopes of the channel banks. The scattered velocity frictions in each section may also be influenced by the irregularity of the riverbeds and the existence of sediment bedload; however, this data was not measured. (Best, J, et al., 1997), based on their study, the presence of bedload sediment increases the near-wall velocity gradient and shear velocity when compared with the clear water values.

The averaged values of $\mathrm{Br}$ - which represents the integration constant of logarithmic velocity distribution - obtained from Clauser method are plotted in Figure 6. The trend of the $B r$-values obtained in this study is also shown in the figure. At the centre of the channel, the $B r$-values are about, $B r=8$, and tend to be smaller reach closer to both sides of the channel bank, in which, Brvalues are approximate $B r=6$. This study has two findings; firstly, in the centre part of the channel, the average $B r$-value is $B r=7.29 \pm 1.45$. This result is in a good agreement with the values quoted in the literature, i.e., $\mathrm{Br}=8.5 \pm 15 \%$ (Reynolds, J. A., 1974). Those values are decreasing when the flow approaches the edges of the channel. Secondly, the flow is a completely rough turbulent flow, since $u * k_{s} / v$ is higher than the value of $u * k_{s} / v>$, as quoted in the literature.

Water flowing in channels is decelerated by the resistance exerted by the channel bed. In uniform open channel flow, there is a definite relationship between the depth-averaged velocity, $\bar{U}_{y}$, the bottom slope, $S_{o}$, the hydraulic radius, $R$, and the roughness characteristics, $k_{s}$, of the channel boundary, in the form of Eq. (2), which is generally called as flow resistance.

For practical purposes, the depth-averaged velocity is often determined from 1-, 2- and/or 3 points velocity measurement $\mathrm{y}=0,2 \mathrm{D}, 0,4 \mathrm{D}$ and $0,8 D$, according to Eqs. (3), (4) and (5) mentioned above. In Table 1 , it is shown the range of data values of $\bar{U}_{y} / U_{1 \text { point }}, \bar{U}_{y} / U_{2 \text { points }}$ and $\bar{U}_{y} /$ $U_{3 \text { points, }}$, as well as the mean and standard deviation values obtained from the data.

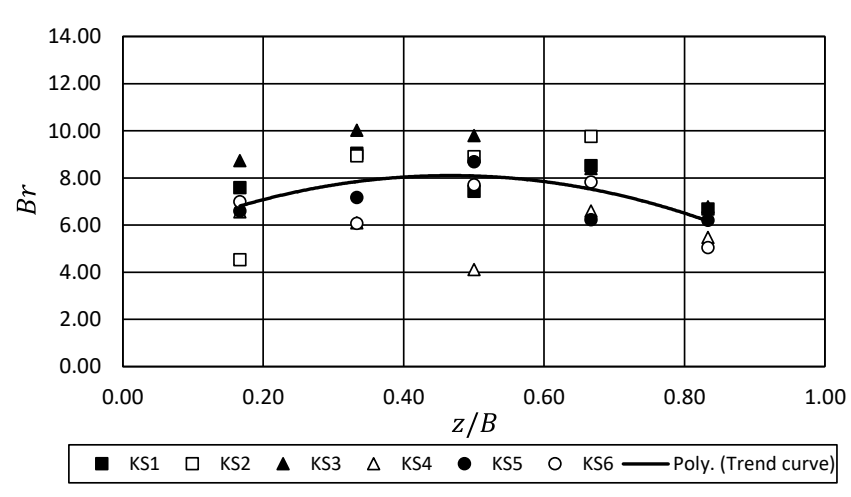

Figure 6. Plott of Br vs. z/B along Kuning River

Based on the data analysed in this study, it can be seen from the table that the mean values of $\bar{U}_{y} / U_{1 \text { point }}, \bar{U}_{y} / U_{2 \text { points }}$ and $\bar{U}_{y} / U_{3 \text { points }}$, are slightly below to one, which mean that the depthaveraged velocities determined from 1-, 2- and 3 points measurement tend to be smaller than those calculated based on the integration of the measured velocity profile over the flow depth; the mean differences, however, are only about $3,8 \%$, $4,5 \%$, and $4,3 \%$ for $1-, 2-$ and 3 points 
measurement, respectively. The values show scattered data in the range of $0,808-1,107$ for 1 point measurement, $0,831-1,018$ for 2 points measurement, and $0,880-1,057$ for 3 points measurement. the Maximum differences are up to $19 \%, 16,9 \%$ and $12 \%$, respectively, for 1,2 and 3 points measurement.

In Figure 7, as a typical example, it is shown the comparison between the depth-averaged velocity determined from the integration of measured velocity profile over the flow depth, $\bar{U}_{y}$, and those obtained from 3 points measurement, $U_{3}$ points, together with Eq. (5). As can be seen from Figure 7 the comparison between the two methods is very satisfactory, which indicate that the depthaveraged velocity, $\bar{U}_{y}$, can be obtained from 1-, 2and/or 3 points measurement together with Eqs. (3), (4) and/or (5).

Table 1. The values of $\bar{U}_{y} / U_{1 \text { point }}, \bar{U}_{y} / U_{2}$ points and $\bar{U}_{y} / U_{3}$ points of present data

\begin{tabular}{lccc}
$\begin{array}{lccc}\text { Present } \\
\text { data }\end{array}$ & $\overline{\boldsymbol{U}}_{\boldsymbol{y}} / \boldsymbol{U}_{\mathbf{1} \text { point }}$ & $\overline{\boldsymbol{U}}_{\boldsymbol{y}} / \boldsymbol{U}_{\mathbf{2} \text { points }}$ & $\overline{\boldsymbol{U}}_{\boldsymbol{y}} / \boldsymbol{U}_{\mathbf{3} \text { points }}$ \\
\hline Range & $0,808-$ & $0,831-$ & $0,880-$ \\
data & 1,107 & 1,018 & 1,057 \\
Mean & 0,962 & 0,955 & 0,957 \\
Standard & 0.066 & 0.0370 & 0.033 \\
Dev. & & & \\
\end{tabular}

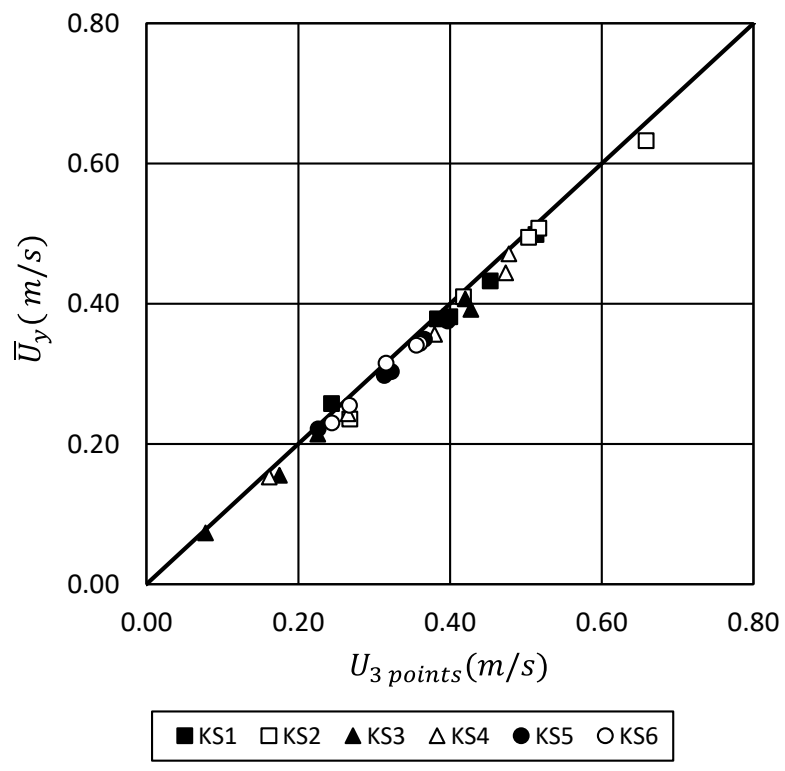

Figure 7. Comparison of depth-averaged velocity, $\bar{U}_{y} v s$. $U_{3 \text { points }}$ together with Eq. (5).

\subsection{Distributions of Suspended Sediment Concentration}

Measurement of suspended sediment concentrations was conducted in the same locations with the velocity profile measurements. Figure 8 gives a typical example of suspended sediment concentration profiles, $C / \bar{C}$ vs. y/D, measured at Section 5, where all of the profiles show their maximum concentration near the riverbed and tend to decrease when approaching the free water surface. The larger of suspended sediment concentrations are observed in the main river channel, as shown for profiles KS5V3, KS5V4, and KS5V5 at the measuring verticals 3, 4, and 5. These findings support the profiles of velocity shown in Figure 2.

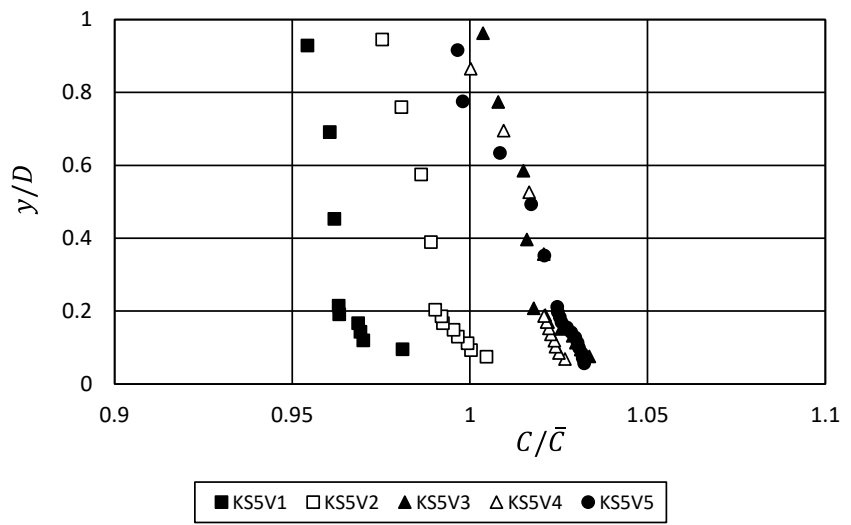

Figure 8. A typical example of suspended sediment concentration profiles at Section 5

Characterization of suspended sediment concentration in a flow is given by Rouse formula, as previously mentioned in Eq. (9). Among several equations to estimate the suspended sediments concentration profile in the literature, Rouse formula can be considered as one of the most famous and widely cited by many works on the mechanics of sediment transport. Rouse equation is derived from Prandt-von Karman logarithmic velocity distribution of 2-Dimensional (2D) flow, that relatively similar to the flow characteristics at the centre part of the channel. Thus, Rouse equation can not be applied to areas closer to the edges of the channel, where the 3D flow observed. In addition to the Rouse equation, the equation of Tanaka and Sugimoto is also commonly used to determine the suspended sediment concentration profiles (Ranga and Raju, 2007). 
Figure 9 presents a comparison between the profiles of calculated suspended sediment concentration by Rouse and by Tanaka-Sugimoto equations and the data measured in the centre (KS3V3) and on the right side (KS3V4) of the channel. As shown in Figure 9, the equations are somewhat valid for the measured data in the centre of the channel; however, away from the centre of the channel, i.e. for profile KS3V4, the equations significantly deviate from the measured data. A study by Kironoto, B.A. \& Yulistiyanto, B. (2009) had similar results to those observed in this study. To apply the equation of Rouse and Tanaka and Sugimoto for the whole cross-section, from the centre to both sides of the channel, the Z-parameter, $Z=w_{S} / u_{*} \kappa$, given in Eqs. (9) and (10) are modified by introducing $\beta$ parameters, in such a way, the Z-parameters in Eq. (11) above - renamed as $Z^{\prime}$-parameters - are given as:

$Z_{R}^{\prime}=\frac{w_{S}}{\beta_{R} u_{*} \kappa}$

$Z_{T S}^{\prime}=\frac{w_{S}}{\beta_{T S} u_{*} \kappa}$

(11b)

where $\beta_{R}$ and $\beta_{T S}$ are parameters introduced in Rouse, and Tanaka \& Sugimoto's equation, respectively. These parameters can be determined by adjusting the measured data of suspended sediment concentration profiles to Rouse and Tanaka and Sugimoto equations. By introducing parameters, $\beta_{R}$ and $\beta_{T S}$, into Rouse and Tanaka and Sugimoto equations. Figure 9 shows a comparison between calculated and measured data of suspended sediment concentration profiles, in which the data coincide quite well to the equations - as compared in Figure $9-$, both in the centre and away from the centre of the channel. Figure 10 and 11 are given the values of $\beta_{R}$ and $\beta_{T S}$ obtained from the data analysed in this study.

As shown in Figures 10 and 11, apart from scattered data observed in the figures, the values of $\beta_{R}$ and $\beta_{T S}$ in the centre of the channel approach to one, and tend to rise in both sides of the channel. In the centre of the channel, where the flow is similar to 2D flow, in the Rouse equation developed, the $\beta$-value equals to one that fits the observed data given in Figures. 10 and 11.

As previously mentioned above for the depthaveraged velocity, for practical purposes, the depth-averaged of suspended sediment concentration is determined from 1-, 2- and 3 points measurement at $\mathrm{y}=0,2 \mathrm{D}, 0,4 \mathrm{D}$ and $0,8 \mathrm{D}$, according to Eqs. (13), (14) and (15) above (Kironoto, B.A, 2008).
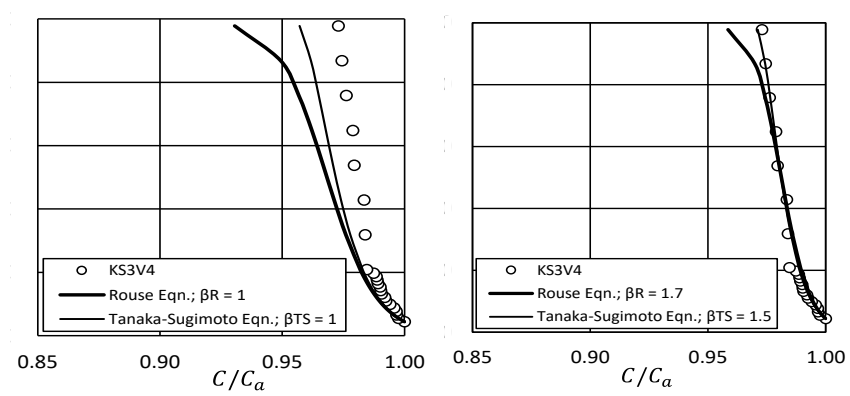

Figure 9. Comparison of measurement data of suspended sediment concentration profile with Rouse and Tanaka and Sugimoto equations for different values of $\beta_{\mathrm{R}}$ and $\beta_{\mathrm{TS}}$

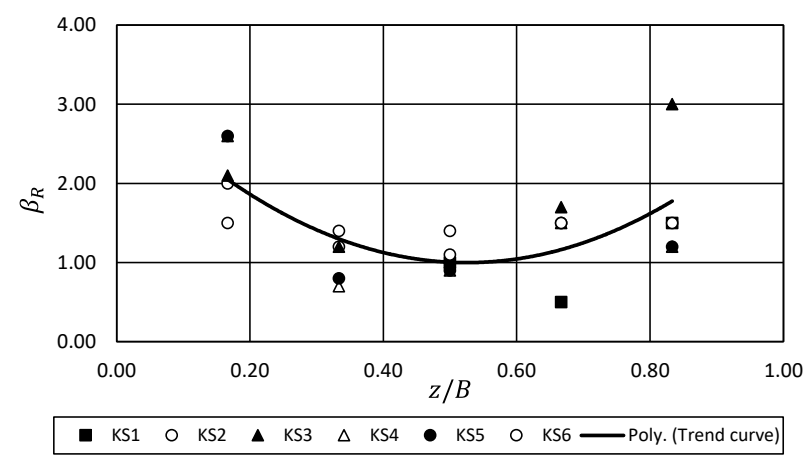

Figure 10. The plot of the values of $\beta_{R}$ against $z / B$

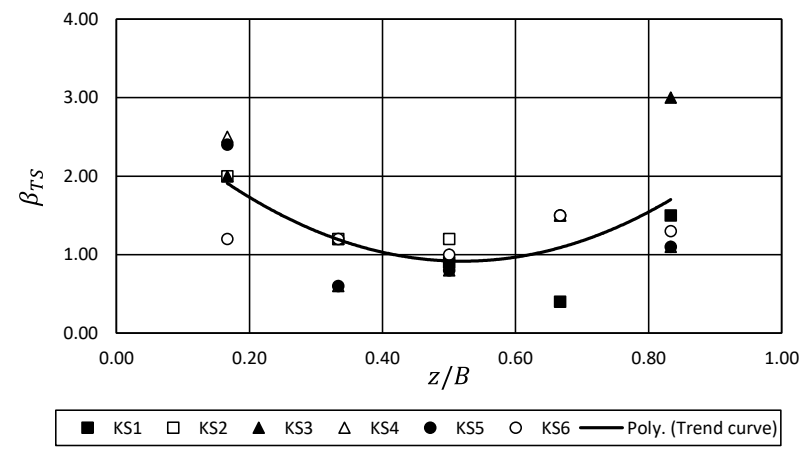

Figure 11. The plot of the values of $\beta_{\mathrm{TS}}$ against $\mathrm{z} / \mathrm{B}$ 
Table 2 shows the range of values of $\bar{C}_{y} / C_{1 \text { point }}$, $\bar{C}_{y} / C_{2 \text { points }}$, and $\left.\bar{C}_{y} / C_{3 \text { points }}\right)$, as well as the mean and standard deviation values obtained in this study. Based on data analysed from this study, it can be seen from Table 2 that the average values of $\bar{C}_{y} / C_{1 \text { point }}, \bar{C}_{y} / C_{2 \text { points }}$, and $\bar{C}_{y} / C_{3 \text { points, }}$ are very close to one, which means that the depthaveraged of suspended sediment concentration can be determined satisfactorily from 1,2 and 3 points measurement; the average difference was only about $1 \%$. The range of values of the data analyzed in this study is $0,960-1,006$ for 1 point measurement, $0,969-1,029$ for 2 points measurement, and $0,974-1,019$ for 3 points measurement, with a maximum difference to $4 \%$, $3,1 \%$ and $2,6 \%$, respectively, for 1,2 and 3 points measurement.

It is shown the data of $\bar{C}_{y} / C_{3}$ points against $z / B$, where the values of $\bar{C}_{y} / C_{3}$ points are very close to one, irrespective of their position in the transverse direction. For a typical example, Figure 12 shows a comparison between the depthaveraged of suspended sediment concentration determined from the integration of the measurement suspended sediment concentration profile over the flow depth, $\bar{U}_{y}$, and those obtained from 3 points measurement, $\mathrm{U}_{3}$ points, together with Eq. (15). Figure 12 shows a comparison between the two methods, which are very satisfactory.

Table 2 . The values of $\bar{C}_{y} / C_{1 \text { point }}, \bar{C}_{y} / C_{2}$ points and $\bar{C}_{y} / C_{3 \text { points }}$ of present data

\begin{tabular}{llll}
\hline Present & $\overline{\boldsymbol{C}}_{\boldsymbol{y}}$ & $\overline{\boldsymbol{C}}_{\boldsymbol{y}}$ & $\overline{\boldsymbol{C}}_{\boldsymbol{y}}$ \\
data & $/ \boldsymbol{C}_{\text {1 point }}$ & $/ \boldsymbol{C}_{\text {2 points }}$ & $\boldsymbol{C}_{\mathbf{3} \text { points }}$ \\
\hline Range & $0,960-$ & $0,969-$ & $0,974-$ \\
data & 1,006 & 1,029 & 1,019 \\
Average & 0,995 & 1,001 & 0,999 \\
St. Dev. & 0.010 & 0.011 & 0.009 \\
\hline
\end{tabular}

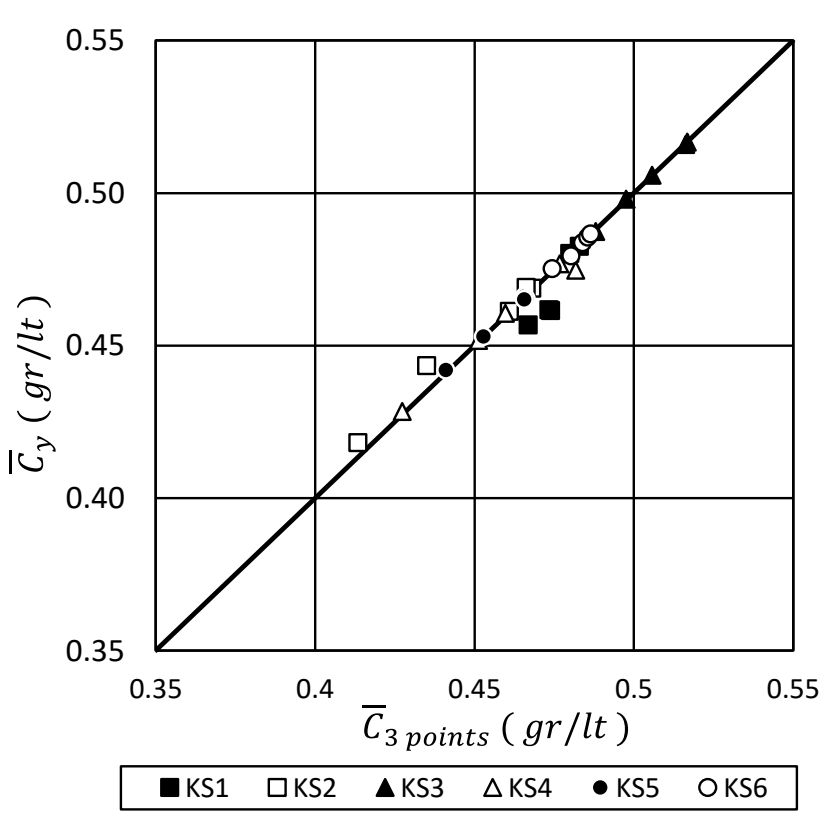

Figure 12. Comparison of the depth-averaged velocity, $\bar{C}_{y}$ vs. $C_{3 \text { points }}$ together with Eq. (15)

\subsection{Discharge of Suspended Sediment}

By using the measurement of flow velocity and concentration of suspended sediment, it is possible to calculate the suspended sediment discharge ratio, presented as $\left(\bar{U}_{y} \bar{C}_{y}\right) /(\bar{U} \bar{C})$, where $\bar{U}_{y}$ and $\bar{C}_{y}$ can be calculated with Eq. (3) and Eq. (12), and $\bar{U}$ and $\bar{C}$ can be calculated with Eq. (7) and Eq. (16) as defined previously. These values are presented in Figure 13, which shows that the suspended sediment discharge ratio in the centre part of the channel is higher than those near the edges of the channel.

According to the curve in Figure 13, if the depthaveraged of velocity and suspended sediment concentration are measured at any locations across the channel section, the suspended sediment discharge can be determined using the following equation:

$Q_{s}=\bar{U} \bar{C}=\left.\left(\bar{U}_{y} \bar{C}_{y}\right)\right|_{z / B}$ 
where $\left.\left(\bar{U}_{y} \bar{C}_{y}\right)\right|_{z / B}$ is the multiplication of the depth-averaged velocity and suspended sediment concentration at a certain distance from the channel sidewall, $z / B$, i.e., multiplication of $\left.\bar{U}_{y}\right|_{z / B}$ and $\left.\llbracket \bar{C}_{y}\right|_{z / B}$.

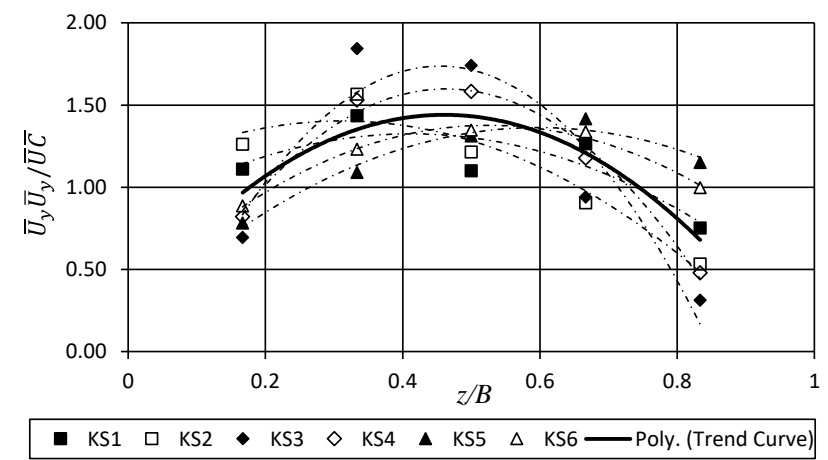

Figure 13. Plot of $\left(\overline{\boldsymbol{U}}_{\boldsymbol{y}} \overline{\boldsymbol{C}}_{\boldsymbol{y}}\right) /(\overline{\boldsymbol{U}} \overline{\boldsymbol{C}})$ vs. $z / B$ along Kuning River

Figure 13 also shows the trend curves of $\left(\bar{U}_{y} \bar{C}_{y}\right) /$ $(\bar{U} \bar{C})$ vs. $z / B$ for each section along Kuning River, from section KS1 to KS6. From the trend of these curves, it can be determined the position of $\mathrm{z} / \mathrm{B}$ for each section where $\left(\bar{U}_{y} \bar{C}_{y}\right) /(\bar{U} \bar{C})=1$. Based on these curves - denoted as the dotted curves in Figure 13 -, we can determine the suspended sediment discharge using the measurements of $\bar{U}_{y}$ and $\bar{C}_{y}$ at any positions in the transverse direction. It can also be seen that the position of $z / B$ where the values of $\left(\left(\bar{U}_{y} \bar{C}_{y}\right) /(\bar{U} \bar{C})=1\right.$ change from one section to another section along Kuning River. Those changes due to the influence of irregularity of each cross-section, the abrupt changes in cross-section geometry, and other types of obstruction and variations, such as riverbed, channel bed slope, channel sidewall slope, roughness, and aquatic vegetations of Kuning River.

In Figure 13, the solid and bold curve indicates the trend curve for all data obtained from 6 different sections from KS1 to KS6. As can be seen from the figure that the position of $z / B$ where $\left(\bar{U}_{y} \bar{C}_{y}\right) /(\bar{U} \bar{C})=1$ occurs at $z / B=0,19$ and $z / B=$ 0,75. Kironoto, B.A \& Yulistiyanto, B, (2010) reports values of $\mathrm{z} / \mathrm{B}=0,2$ and 0,8 for rectangle and prismatic channel of laboratory and of field data, whereas for trapezoid and prismatic of field channel with the channel side wall slopes variate from $1: 1,0$ to $1: 1,6$ (vertical to horizontal ratio), Kironoto, B.A \& Yulistiyanto, B. (2016b) reported the values of $\mathrm{z} / \mathrm{B}=0,25$ and 0,75 .

\section{CONCLUSIONS}

According to data analysis and discussion, some points can be concluded :

a. Based on measurements of the velocity profile, the highest velocity occurs in the centre part of the channel, and then decrease at a location near the edges of the channel. Rouse and Tanaka and Sugimoto equations can still be used to represent the measured data of suspended sediment concentration in the centre of the channel; however, a parameter should be introduced, namely as $\beta$-parameter when the equation is used to estimate velocity and concentration near the edge of the channel.

b. The Clauser method can be used to determine the friction velocity, $\mathrm{u}^{*}$, along Kuning river. The values of the integration constant of logarithmic velocity distribution, $\mathrm{Br}$, tend to be smaller at the location near the edges of the channel. The suspended sediment discharge ratio presented as $\left(\bar{U}_{y} \bar{C}_{y}\right) /(\bar{U} \bar{C})$ - where $\bar{U}_{y}, \bar{U}, \bar{C}_{y}$, and $\bar{C}$ are the average depth and the average cross-section. Velocity and suspended sediment concentration are higher in the centre part of the channel than those near the edges of the channel.

c. According to the data measured at six different locations along Kuning River, the position of $\mathrm{z} / \mathrm{B}$ where the value of $\left(\bar{U}_{y} \bar{C}_{y}\right) /(\bar{U} \bar{C})=1$ located at $\mathrm{z} / \mathrm{B}=0,19$ and $\mathrm{z} / \mathrm{B}=0,75$. For practical purposes, the depth-averaged of velocity and suspended sediment concentration can be determined from 1, 2 and 3 points measurement at $\mathrm{y}=0,2 \mathrm{D}, 0,4 \mathrm{D}$ and 0,8D together with Eqs. (4), (5), and (6), and Eqs. (13), (14), and (15).

\section{ACKNOWLEDGMENTS}

The authors would like to express their gratitude to the Research and Community Service 
Institution (LPPM) Universitas Gadjah Mada for providing fund through the We also thank to the Hydraulics Laboratory, Department of Civil and Environmental Engineering, Faculty of Engineering, Universitas Gadjah Mada, for the equipment and facilities that have been provided during the field investigation.entire study.

\section{REFERENCES}

Bartram, J \& Balance, R, 1996. A Practical Guide to the Design and Implementation of Freshwater Quality Studies and Monitoring Programs. Water Quality Monitoring. New York, UNEP/WHO.

Best, J, Bennett, S, Bridge, J \& Leeder, M, 1997. Turbulence Modulation and Particle Velocities over Flat Sand Beds at Low Transport Rates.. J. Hydraul. Eng., Volume 123, pp. 1118-1129..

Cardoso, A. H, Graf, W.H \& Gust, G, 1989. Uniform flow in smooth open-channel.. JHR, IAHR, Volume 27(5), pp. 603-616.

Garde, R.J \& Raju, K.G.R. , 1997. Mechanics of sediment transportations and alluvial stream problems, New Delhi: 2nd Edition Wiley Eastern Limited.

Giarto, B.R, 2016. Distributions of Suspended Sediment Concentration in Natural River (Case Study at Opak and Kuning Rivers), Yogyakarta: Universitas Gadjah Mada.

Gray. J.R \& Landers, M.N, 2014. Measuring suspended sediment. In: Ahuja S. (ed.) Comprehensive Water Quality and Purification. United States of America: Elsevier Inc., Volume 1, pp. 157-204.

Guo, J \& Julien, P.Y, 2001. Turbulent velocity profiles in sediment-laden flows.. J. Hydr. Res, Volume 39.

Kiptiah, M, 2016. Distributions of Flow Velocity in Natural River (Case Study at Opak and Kuning Rivers), Yogyakarta: Universitas Gadjah Mada.

Kironoto, B.A. \& Yulistiyanto, B. , 2016a. The Simplified of Suspended Sediment Measurement Method for Predicting Suspended Sediment Load as A Basic of Reservoir Capacity Design as
Renewable Energy Resource. Int. J. of Renewable Energy Res, Volume 6.

Kironoto, B.A. \& Yulistiyanto, B, 2016. The Simplified of Suspended Sediment Measurement Method for Predicting Suspended Sediment Load as A Basic of Reservoir Capacity Design as Renewable Energy Resource. Int. J. of Renewable Energy Res., Volume 6(1).

Kironoto, B.A, 2008. Depth-averaged suspended sediment concentration based on 1,2 , and 3 points of measurement in uniform open channel flow. Dinamika Teknik Sipil, Volume 8, p. 59 - 71.

Kironoto, B.A \& Yulistiyanto, B. , 2016b. Suspended Sediment Sampling Method for Determining Suspended Sediment Discharge in Artificial Channel and Natural River., Yogyakarta: Competitive Research Grant Report, Research and Community Service Institution (LPPM), Universitas Gadjah Mada.

Kironoto, B.A \& Yulistiyanto, B, 2009. The validity of the Rouse equation for predicting the transversal suspended sediment concentration profiles in uniform open channel flow. Yogyakarta, International Conference on Sustainable Development for Water and Wastewater Treatment, MUWAREC-YK09, Universitas Gadjah Mada.

Kironoto, B.A \& Yulistiyanto, B, 2010. Study on suspended sediment sampling location in a transversal direction of uniform open channel flow. Yogyakarta, Int. Workshop on Multimodal Sediment Disasters Triggered by Heavy Rainfall and Earthquake and the Countermeasures, Universitas Gadjah Mada.

Kironoto, B.A \& Yulistiyanto, B, 2016. Suspended Sediment Sampling Method for Determining Suspended Sediment Discharge in Artificial Channel and Natural River., Yogyakarta: Competitive Research Grant Report, Research and Community Service Institution (LPPM), Universitas Gadjah Mada.

Kironoto, B.A \& Yulistiyanto, B, 2016. Suspended Sediment Sampling Method for Determining Suspended Sediment Discharge in Artificial Channel 
and Natural River., Yogyakarta: Competitive Research Grant Report, Research and Community Service Institution (LPPM), Universitas Gadjah Mada.

Lv, S, et al., 2015. Laboratory measurement of suspended sediment concentration by using $A D V$. s.l., Proceedings of the 6th International Asia Conference on Industrial Engineering and Management Innovation.

Muste \& Patel, 1997. Velocity profiles for particles and liquid in open-channel flow with suspended sediment. Hydr.Eng, Volume 123(9), pp. 742-751.

Reynolds, J. A., 1974. Turbulent Flows in Engineering, London, Great Britain.: John Wiley \& sons Ltd.
Shah-Fairbank Shah-Fairbank, S., Julien, P. \& Bai, 2011. Total sediment load from semep using depth-integrated concentration measurements.. J. Hydr. Eng, 137(No. 12), pp. 1606-1614.

Shamei \& Kaedi, 2016. Suspended sediment concentration estimation by stacking the genetic programming and neuro-fuzzy predictions.. Applied Soft Computing, Volume Vol. 45, p. 187196.

Tantowi \& M. Lutfi, 2016. Characteristic of Suspended Sediment Flow at Kuning River ( Determination Based on 1, 2, and 3 Points), Yogyakarta: Civil Eng. And Env. Department, Universitas Gadjah Mada. 